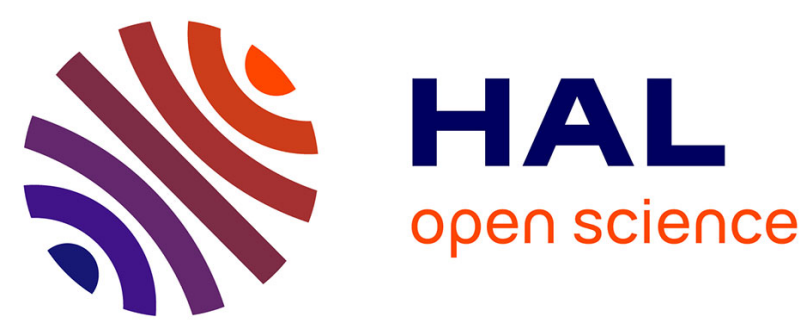

\title{
Synthesis of Alkyl Sulfur-Functionalized Oleic Acid-Based Polymethacrylates and Their Application as Viscosity Index Improvers in a Mineral Paraffinic Lube Oil
}

Juliette Lomège, Claire Negrell, Jean-jacques Robin, Vincent Lapinte, Sylvain Caillol

\section{To cite this version:}

Juliette Lomège, Claire Negrell, Jean-jacques Robin, Vincent Lapinte, Sylvain Caillol. Synthesis of Alkyl Sulfur-Functionalized Oleic Acid-Based Polymethacrylates and Their Application as Viscosity Index Improvers in a Mineral Paraffinic Lube Oil. Journal of the American Oil Chemists' Society, 2020, 97 (3), pp.309-318. 10.1002/aocs.12316 . hal-02500509

\author{
HAL Id: hal-02500509 \\ https://hal.science/hal-02500509
}

Submitted on 15 May 2020

HAL is a multi-disciplinary open access archive for the deposit and dissemination of scientific research documents, whether they are published or not. The documents may come from teaching and research institutions in France or abroad, or from public or private research centers.
L'archive ouverte pluridisciplinaire HAL, est destinée au dépôt et à la diffusion de documents scientifiques de niveau recherche, publiés ou non, émanant des établissements d'enseignement et de recherche français ou étrangers, des laboratoires publics ou privés. 


\title{
Synthesis of alkyl sulfur-functionalized oleic acid-based polymethacrylates and their application as viscosity index improvers in a mineral paraffinic lube oil
}

\author{
Juliette Lomège, Claire Negrell, Jean-Jacques Robin, Vincent Lapinte, Sylvain Caillol* \\ Institut Charles Gerhardt Montpellier UMR 5253, Univ Montpellier, CNRS, ENSCM, Université de \\ Montpellier, CC1702, Place Eugène Bataillon, 34095 Montpellier Cedex 5, France \\ * Correspondence to: S. Caillol (E - mail: sylvain.caillol@enscm.fr)
}

Keywords: Oleic acid; Thiol-ene coupling; Methacrylate; Radical polymerization; Viscosity Index Improver; Lubricant application

\section{Abstract}

This work describes the synthesis of alkyl sulfur-functionalized polymethacrylate-based Viscosity Index Improvers (VII)s derived from oleic acid for mineral paraffinic lubricating oils. In this strategy, oleic acid was firstly quantitatively ramified by alkyl thiols containing long aliphatic chains through thiol-ene coupling as demonstrated by ${ }^{1} \mathrm{H}$ NMR spectroscopy with the complete consumption of oleic acid internal double bonds. The resulting alkyl sulfurfunctionalized oleic acid-based derivatives were methacrylated through Steglich esterification in order to afford highly suitable hydrophobic oleic acid-based monomers which, as far as we know, have not been described yet in the current literature. High polymethacrylate molecular weights were reached through radical polymerization despite the long alkyl pendant chains contained in their backbones. Finally, the resulting alkyl sulfur-functionalized oleic acidbased polymethacrylates have been blended in a mineral paraffinic oil (MPO) of reference at 5 wt. $\%$ and evaluated as VIIs. Rheological measurements revealed that polymer thickening powers were significantly improved in oil with temperature and promoted by increasing the pendant alkyl thiol contained in polymer backbones. Moreover, the viscosity index of MPO was significantly improved with the addition of both synthesized homopolymers which confirmed their efficiency as VIIs. In the meantime, these results have been compared to a previously reported polymer, the poly(2-(methacryloyloxy)ethyl oleate) (PMAEO) which demonstrated a lower VII efficiency compared to its analogous polymethacrylates containing an additional alkyl chain in their pendant chains. 


\section{Introduction}

The viscosity is one of the main important characteristics of lubricating oils (Neveu et al., 2012; Bartz et al., 1978). In mechanical systems, fluid viscosity leads to the formation and strength of lubricating films that protect the metal parts from friction and wear. Therefore, it is essential that the viscosity of a lubricant change minimally with fluctuating operating conditions (Eskici et al., 2008). In the industry, the viscosity-temperature dependency of a lubricant is evaluated by the measurement of the viscosity index (VI) which defines the quality of a lubricant and its application temperature range (Stanciu, 2012). According to the calculation method of the VI, lubricants with a high VI exhibit a low viscosity variation with temperature and are generally preferred in most machines. Therefore, in order to provide performant lubricant, base oils are generally formulated with specific high molecular weight polymer additives known as Viscosity Index Improvers (VII)s (Martini et al., 2018; Almeida et al., 2014; Rattan et al., 2017). The addition of these polymers, which display viscosity thickening power as a result of their high molecular weight, are able to minimize viscosity variation in temperature, increase the VI, and thus, widen the application temperature range of lubricants. Commonly used VIIs for mineral lubricating oils are poly(alkylmethacrylates) (PMA)s (Ahmed et al., 2017; Akhmedov et al., 1993; Mohamad et al., 2012; Horne et al., 1949). The mechanism of action of such additives is based on their difference of solubility at low and high temperatures, resulting in an improvement of the additive thickening power in temperature (Selby, 1958; Ramasamy et al., 2016; Covitch et al., 2015; Müller, 1978). Indeed, as PMAs show only poor solubility in mineral oil at low temperatures (coil polymer contraction), it induces a relatively low viscosity contribution. However, PMAs show improved solubility as temperature increases (coil polymer expansion) inducing higher thickening power which thus limits the loss of viscosity of the fluid at elevated temperatures.

Even if the afore-mentioned additives, essentially obtained from fossil feedstock (Neveu et al., 2012; Cai et al., 2015), fulfill the requirements in term of viscosity tailoring, there is a growing demand for additives originated from renewable feedstock (Ghosh et al., 2014; Ghosh, 2014; Ghosh et al., 2017; Ghosh et al., 2017). In this context, it is advantageous to investigate novel biobased polymers showing close chemical structures and/or comparable technical performances to the currently used fossil-based polymeric VII. Plant oils and their fatty acids (FA) derivatives represent a perfect feedstock to achieve this goal. Indeed, polymers originated from these renewable resources have many advantages including the 
hydrophobicity required to this kind of additives that must be soluble in mineral oils, an important flexibility in chemical structures and properties (as seen from the large series of papers (Caillol et al., 2012; Stemmelen et al., 2011; Pelletier et al., 2006) and reviews (Lligadas et al., 2013; Montero de Espinosa et al., 2011), and the monomers needed for their synthesis are considered feasible on a large scale due to the wide availability of plant oils. In this environmental context, our previous works reported the synthesis of various polymers containing methacrylate FA moieties $(\mathrm{C} 12-\mathrm{C} 18)$ through radical polymerization which proved to be promising VIIs for a reference mineral paraffinic oil (MPO) (Lomège et al., 2018). Moreover, the results of this study have shown that the thickening efficiency of the resulting VIIs can be promoted by using preferentially high molecular weight polymers as well as by using methacrylate monomers derived from long FA chain length such as oleic acid (C18:1) as described in Fig. 1.

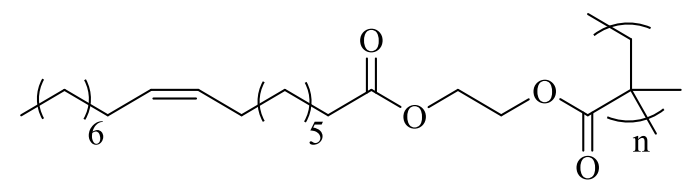

Fig. 1: Chemical structure of the poly(2-(methacryloyloxy)ethyl oleate)-based VII (PMAEO)

Hence, in order to afford even more performant VIIs with improved thickening power in MPO, the chemical structure of PMAEO can be modified by grafting an additional pendant alkyl chain on its pendant chain via the available internal double bonds. Among many existing reactions involving these unsaturations, the addition of alkyl thiols to olefins is a promising strategy to achieve this goal since it is nowadays frequently employed for the synthesis and polymerization of renewable monomers from vegetable oils (Ionescu et al., 2015; Bantchev et al., 2009; Biresaw et al., 2011). For instance, Desroches et al. previously reported the successful quantitative thiol-ene coupling of mercaptoethanol on oleic acid unsaturations (Desroches et al., 2011). Alternatively to the modification of monomers, this reaction can also be employed in a post-polymerization functionalization approach, if the polymer still contain vinyl groups after polymerization (Bowman et al., 2010; Vidal et al., 2015; Vidal et al., 2016). Then, thiol-ene coupling of oleic acid with alkyl thiols containing long aliphatic chains could yield suitable highly hydrophobic monomers for providing high performant polymer-based VIIs for MPO.

The approach followed in this work consisted of synthesizing oleic acid-based monomer structures to afford polymeric VIIs with high thickening power efficiency in MPO. For this 
purpose, oleic acid, which is widely available in most of the plant oils and therefore costeffective, has been firstly functionalized by thiol-ene coupling with two alkyl thiols including either 1-dodecanethiol or 1-octadecanethiol. Then, the two resulting alkyl sulfurfunctionalized derivatives were methacrylated by Steglich esterification to provide suitable monomers for radical polymerization. Finally, the oleic acid-based polymers contaning pendant aliphatic chains with ramified alkyl sulfur were mixed in a mineral paraffinic oil and evaluated as VIIs by monitoring the tendency of their thickening power in temperature through rheological measurements. All monomer and polymer structures were determined by ${ }^{1} \mathrm{H}$ NMR spectroscopy and characterized by TGA, DSC and SEC.

\section{Materials and methods}

\section{Reagents}

Oleic acid (OA, $98 \%$ ) was purchased from Fisher Scientific while dicyclohexylcarbodiimide (DCC), dimethylaminopyridine (DMAP, $99 \%$ ), 2-hydroethyl methacrylate (HEMA, 99\%), 1-dodecanethiol (98\%), 1-octadecanethiol (98\%), benzoyl peroxide (BPO, with $25 \mathrm{~m}$. \% $\left.\mathrm{H}_{2} \mathrm{O}\right)$ and deuterated chloroform $\left(\mathrm{CDCl}_{3}\right)$ were purchased from Sigma-Aldrich and used as received except azobis(isobutyronitrile) (AIBN, $98 \%$ ) which was recrystallized in methanol before being used. All solvents including tetrahydrofuran (THF, 99 $\%)$, toluene (99\%), methanol $(\mathrm{MeOH}, 99 \%)$, cyclohexane (CY, $98 \%)$ and ethyl acetate (EtOAc, $98 \%$ ) were obtained from VWR and were used without further purification. A mineral paraffinic oil (MPO) was kindly supplied by ITERG. The lubricating oil characteristics are detailed in Table 1. 
Table 1: Mineral paraffinic oil (MPO) properties (Technical data)

\begin{tabular}{|c|c|}
\hline \multicolumn{2}{|l|}{ Properties } \\
\hline Density at $20^{\circ} \mathrm{C}\left({\left.\mathrm{g} . \mathrm{cm}^{-3}\right)}^{-3}\right.$ & 0.8503 \\
\hline Kinematic viscosity at $40{ }^{\circ} \mathrm{C}\left(\mathrm{mm}^{2} \cdot \mathrm{s}^{-1}\right)$ & $26.92 *$ \\
\hline Kinematic viscosity at $100{ }^{\circ} \mathrm{C}\left(\mathrm{mm}^{2} \cdot \mathrm{s}^{-1}\right)$ & $4.87 *$ \\
\hline Viscosity Index & 103 \\
\hline Pour Point $\left({ }^{\circ} \mathbf{C}\right)$ & -15 \\
\hline Thermal stability (at $5 \%$ weight loss, ${ }^{\circ} \mathrm{C}$ ) & 200 \\
\hline
\end{tabular}

*: calculated through rheological measurements (see instrumentation part below).

\section{Instrumentations}

\section{Nuclear magnetic resonance (NMR)}

${ }^{1} \mathrm{H}$ NMR spectra were acquired using a Bruker Avance $400 \mathrm{MHz}$ spectrometer equipped with a QNP z-gradient probe at room temperature. NMR samples were prepared as follows: $10 \mathrm{mg}$ of product for ${ }^{1} \mathrm{H}$ experiment in around $0.4 \mathrm{~mL}$ of $\mathrm{CDCl}_{3}$. The chemical shifts were reported in part per million relative to tetramethylsilane. Spin multiplicity is expressed by s = singlet, $\mathrm{d}=$ doublet, $\mathrm{t}=$ triplet, $\mathrm{q}=$ quartet, $\mathrm{m}=$ multiplet.

\section{Size exclusion chromatography (SEC)}

Molar mass and molar mass distribution (dispersity, Đ) of polymers were determined by size exclusion chromatography using a GPC 50 Varian equipped with an RI refractive index detector. The system used two PLgel $5 \mu \mathrm{m}$ Mixed D columns with THF as eluent with a flow rate of $1 \mathrm{~mL} \cdot \mathrm{min}^{-1}$. Poly(methyl methacrylate) (PMMA) standards were used for the calibration. The typical sample concentration was $5 \mathrm{mg} \cdot \mathrm{mL}^{-1}$.

\section{Thermogravimetric analysis (TGA)}

Thermogravimetric analyses (TGA) were performed using a TGA Q50 (TA instrument) at a heating rate of $10^{\circ} \mathrm{C} \cdot \mathrm{min}^{-1}$. Approximately $10 \mathrm{mg}$ of sample were placed in an aluminum pan and heated from room temperature to $500{ }^{\circ} \mathrm{C}$ under nitrogen atmosphere $\left(60 \mathrm{~mL} \cdot \mathrm{min}^{-1}\right)$.

\section{Differential scanning calorimetry (DSC)}

Differential scanning calorimetry (DSC) analyses were carried out using a NETZSCH Maia DSC200F3 calorimeter. Constant calibration was performed using indium, $n$-octadecane and $n$-octane standards. Nitrogen was used as the purge gas. 10-15 mg samples were sealed in aluminum pans. The thermal properties were analyzed at $20^{\circ} \mathrm{C} \cdot \mathrm{min}^{-1}$ between -100 and 
$100^{\circ} \mathrm{C}$. Thermograms were recorded during the second heating ramp after removing thermal history of the polymer was removed during first heating scan.

\section{Rheometer}

Rheological investigations are executed by using a MCR 302 rheometer by Anton-Paar in plate-plate geometry with a diameter of $\mathrm{d}=25 \mathrm{~mm}$. The dynamic viscosity of oil-polymer blends was measured from 0 to $100{ }^{\circ} \mathrm{C}$ at a shear rate of $100 \mathrm{~s}^{-1}$ and the relative viscosity (RV) in function of temperature was calculated by using the equation below:

$$
R V=\frac{\mu}{\mu_{0}}
$$

where $\mu$ and $\mu_{0}$ correspond respectively to the dynamic viscosity of the polymer solution and the dynamic viscosity of the pure solvent.

\section{Densimeter}

Density measurements of all formulations were performed on the DMA 4100M densimeter of Anton Paar at 40 and $100{ }^{\circ} \mathrm{C}$. Before starting the test, the oil-polymer blends were all stirred at $100{ }^{\circ} \mathrm{C}$ during 1 hour to ensure a good homogenization. Then, samples were cooled at the temperature of measurement and approximatively $1 \mathrm{~mL}$ is loaded into the densimeter to start the test. The kinematic viscosity of oil-polymer blends at 40 and $100{ }^{\circ} \mathrm{C}$ were deducted by following the equation:

$$
v=\frac{\mu}{\rho}
$$

where $v, \mu$, and $\rho$ correspond respectively to the fluid kinematic viscosity $\left(\mathrm{mm}^{2} . \mathrm{s}^{-1}\right)$, the fluid dynamic viscosity $\left(\mathrm{Pa}_{\mathrm{s}}{ }^{-1}\right)$, and the fluid density $\left(\mathrm{g} \cdot \mathrm{cm}^{-3}\right)$. Finally, the viscosity indexes of the formulations were calculated according to the ASTM D2270-10 method by using the values of kinematic viscosity of polymer solutions at 40 and $100{ }^{\circ} \mathrm{C}$.

\section{Preparation of alkyl sulfur-functionalized from oleic acid through thiol-ene coupling}

\section{Synthesis of 9-(octadecylthio)oleic acid $\left(\mathrm{OA}_{\mathrm{SC} 18}\right)$}

Oleic acid (0.106 mol, $30.0 \mathrm{~g})$ was charged in bulk in a $200 \mathrm{~mL}$ two neck round bottom flask. Then AIBN (0.2 eq, $21 \mathrm{mmol}, 3.5 \mathrm{~g})$ and 1-octadecanethiol (3 eq, $0.319 \mathrm{~mol}, 91.5 \mathrm{~g})$ 
was added into the reaction mixture and stirred at $70{ }^{\circ} \mathrm{C}$. After $24 \mathrm{~h}$ of reaction, a second addition of AIBN is added to the solution and the reaction is continued $24 \mathrm{~h}$ more. After the complete conversion of the internal unsaturation of oleic acid by thiol-ene coupling, the resulting oleic acid-based thiol derivative $\left(\mathrm{OA}_{\mathrm{SC} 18}\right)$ was purified through flash chromatography using silica gel as stationary phase and CY-EtOAc (95:5, v/v) as eluent (yield $=78 \%$ ). Its structure was confirmed by ${ }^{1} \mathrm{H}$ NMR (Fig. 2, (A)).

OA $_{\text {SC18 }}: \delta\left(\mathrm{ppm}, 400 \mathrm{MHz}, \mathrm{CDCl}_{3}\right): 2.54-2.52(-\mathrm{S}-\mathrm{CH}-, 1 \mathrm{H}, \mathrm{m}), 2.46\left(-\mathrm{CH}_{2}-\mathrm{S}-, 2 \mathrm{H}, \mathrm{t}, \mathrm{J}=7.4\right.$ $\mathrm{Hz}), 2.34\left(\mathrm{O}=\mathrm{C}-\mathrm{C} \mathbf{H}_{2}, 2 \mathrm{H}, \mathrm{t}, \mathrm{J}=7.5 \mathrm{~Hz}\right), 1.63-1.59\left(\mathbf{H}_{2} \mathrm{C}-\mathrm{H}_{2} \mathrm{C}-\mathrm{C}=\mathrm{O}, 4 \mathrm{H}, \mathrm{m}\right), 1.51\left(-\mathrm{CH}_{2}-\mathrm{CH}-\right.$ $\left.\mathrm{CH}_{2}, 4 \mathrm{H}, \mathrm{m}\right), 1.43-1.24\left(-\left(\mathrm{CH}_{2}\right)_{6}-\mathrm{CH}_{2}-\mathrm{CH}-\mathrm{CH}_{2}-\left(\mathrm{CH}_{2}\right)_{5}\right.$ and $\left.\mathrm{S}-\mathrm{CH}_{2}-\left(\mathrm{CH}_{2}\right)_{16}-\mathrm{CH}_{3}, 54 \mathrm{H}, \mathrm{m}\right)$, $0.87\left(-\mathrm{CH}_{2}-\mathrm{CH}_{3}\right.$ and $\left.\mathrm{S}-\mathrm{CH}_{2}-\left(\mathrm{CH}_{2}\right)_{16}-\mathrm{CH}_{3}, 6 \mathrm{H}, \mathrm{t}, \mathrm{J}=6.4 \mathrm{~Hz}\right)$.

\section{Synthesis of 9-(dodecylthio)oleic acid $\left(\mathrm{OA}_{\mathrm{SC12}}\right)$}

The alkyl sulfur-functionalized oleic acid derivative 9-(dodecylthio)oleic acid was obtained by following the same procedure than $\mathrm{OA}_{\mathrm{SC} 18}$ using 1-octadecanethiol instead of 1dodecanethiol (yield $=83 \%$ ) as reported previsously (Lomège et al., 2018). Its chemical structure was confirmed by ${ }^{1} \mathrm{H}$ NMR (Fig. SI-1, (B)).

$\mathbf{O A}_{\mathbf{S C 1 2}}: \delta$ (ppm, $\left.400 \mathrm{MHz}, \mathrm{CDCl}_{3}\right): 2.54$ (-S-CH-, 1H, m), $2.46\left(-\mathrm{CH}_{2}-\mathrm{S}-, 2 \mathrm{H}, \mathrm{t}, \mathrm{J}=7.4 \mathrm{~Hz}\right)$, $2.34\left(\mathrm{O}=\mathrm{C}-\mathrm{CH}_{2}, 2 \mathrm{H}, \mathrm{t}, \mathrm{J}=7.5 \mathrm{~Hz}\right), 1.63-1.59\left(\mathbf{H}_{2} \mathrm{C}-\mathrm{H}_{2} \mathrm{C}-\mathrm{C}=\mathrm{O}, 4 \mathrm{H}, \mathrm{m}\right), 1.51\left(-\mathrm{CH}_{2}-\mathrm{CH}-\mathrm{CH} \mathbf{H}_{2}\right.$ $4 \mathrm{H}, \mathrm{m}), 1.43-1.24\left(-\left(\mathrm{CH}_{2}\right)_{6}-\mathrm{CH}_{2}-\mathrm{CH}-\mathrm{CH}_{2}-\left(\mathrm{CH}_{2}\right)_{5}\right.$ and $\left.\mathrm{S}_{-}-\mathrm{CH}_{2}-\left(\mathrm{CH}_{2}\right)_{10}-\mathrm{CH}_{3}, 42 \mathrm{H}, \mathrm{m}\right), 0.87$ ($\mathrm{CH}_{2}-\mathrm{CH}_{3}$ and $\left.\mathrm{S}-\mathrm{CH}_{2}-\left(\mathrm{CH}_{2}\right)_{10}-\mathrm{CH}_{3}, 6 \mathrm{H}, \mathrm{t}, \mathrm{J}=6.4 \mathrm{~Hz}\right)$.

\section{Preparation of methacrylate monomers from alkyl sulfur- functionalized oleic acid-based derivatives}

\section{Synthesis of fatty ester 2-(methacryloyloxy)ethyl 9-( octadecylthio)oleate $\left(\right.$ MAEO $\left._{\mathrm{SC18}}\right)$}

$\mathrm{OA}_{\mathrm{SC} 18}(0.031 \mathrm{~mol}, 17,6.0 \mathrm{~g})$, DMAP $(0.016 \mathrm{~mol}, 1.89 \mathrm{~g})$ and HEMA $(0.062 \mathrm{~mol}, 8.07 \mathrm{~g})$ were introduced into a two neck round bottom flask with $200 \mathrm{~mL}$ of THF and stirred at room temperature. Then, the reaction mixture was put in an ice-water bath. In a separate beaker, DCC (0.034 mol, $7.03 \mathrm{~g})$ was dissolved in a minimum of THF and was added dropwise to the solution mixture. The ice-water bath was removed after complete addition of DCC. After 24 
$\mathrm{h}$, the white precipitated urea was filtered off and THF was removed by rotary evaporator. Then, the resulting ester was dissolved in toluene and washed twice with distilled water and then dried under vacuum. The purified monomer $\mathrm{MAEO}_{\mathrm{SC} 12}$ was obtained in $75 \%$ yield. Its chemical structure was confirmed by ${ }^{1} \mathrm{H}$ NMR (Fig. 2, (B)).

MAEO $_{\text {SC18: }} \delta\left(\mathrm{ppm}, 400 \mathrm{MHz}, \mathrm{CDCl}_{3}\right): 6.12$ and $5.59\left(\mathrm{C}=\mathrm{CH}_{2}, 2 \mathrm{H}, \mathrm{s}\right), 4.35-4.32\left(\mathrm{OCH}_{2}-\right.$ $\mathrm{CH}_{2} \mathrm{O}, 4 \mathrm{H}$, ), 2.54-2.52 (-S-CH-, 1H, m), $2.46\left(-\mathrm{CH}_{2}-\mathrm{S}-\right.$, , 2H, t, J=7.4 Hz), $2.32(\mathrm{O}=\mathrm{C}-\mathrm{CH}$, $2 \mathrm{H}, \mathrm{t}, \mathrm{J}=7.5 \mathrm{~Hz})$ ) $, 1.95\left(\mathrm{CH}_{3}-\mathrm{C}, \mathrm{s}\right), 1.63-1.59\left(\mathbf{H}_{2} \mathrm{C}-\mathrm{H}_{2} \mathrm{C}-\mathrm{C}=\mathrm{O}, 4 \mathrm{H}, \mathrm{m}\right), 1.54-1.49\left(-\mathrm{CH}_{2}-\mathrm{CH}-\right.$ $\left.\mathrm{CH}_{2}, 4 \mathrm{H}, \mathrm{m}\right), 1.45-1.26\left(-\left(\mathrm{CH}_{2}\right)_{6}-\mathrm{CH}_{2}-\mathrm{CH}-\mathrm{CH}_{2}-\left(\mathrm{CH}_{2}\right)_{5}\right.$ and $\left.\mathrm{S}-\mathrm{CH}_{2}-\left(\mathrm{CH}_{2}\right)_{16}-\mathrm{CH}_{3}, 54 \mathrm{H}, \mathrm{m}\right)$, $0.88\left(-\mathrm{CH}_{2}-\mathrm{CH}_{3}\right.$ and $\left.\mathrm{S}-\mathrm{CH}_{2}-\left(\mathrm{CH}_{2}\right)_{16}-\mathrm{CH}_{3}, 6 \mathrm{H}, \mathrm{t}, \mathrm{J}=6.4 \mathrm{~Hz}\right)$.

\section{Synthesis of fatty ester 2-(methacryloyloxy)ethyl 4-(dodecylthio)oleate $\left(\right.$ MAEO $\left._{\mathrm{SC12}}\right)$}

The alkyl sulfur-functionalized oleic acid-based methacrylate monomer was obtained by following the same procedure than $\mathrm{MAEO}_{\mathrm{SC} 18}$ as reported previsously (Lomège et al., 2018). (yield $=70 \%$ ). Its chemical structure was confirmed by ${ }^{1} \mathrm{H}$ NMR (Fig. SI-2, (A))

MAEO $_{\mathrm{SC12}_{2}:} \delta\left(\mathrm{ppm}, 400 \mathrm{MHz}, \mathrm{CDCl}_{3}\right): 6.13$ and $5.59\left(\mathrm{C}=\mathrm{CH}_{2}, 2 \mathrm{H}, \mathrm{s}\right), 4.35-4.32\left(\mathrm{OCH}_{2}-\right.$

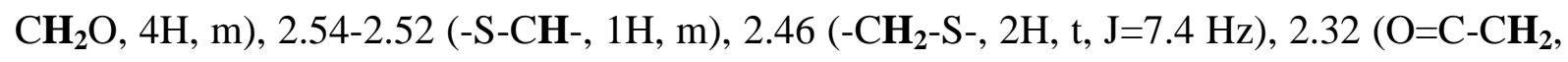
$2 \mathrm{H}, \mathrm{t}, \mathrm{J}=7.5 \mathrm{~Hz}), 1.95\left(\mathrm{CH}_{3}-\mathrm{C}, \mathrm{s}\right), 1.63-1.59\left(\mathbf{H}_{2} \mathrm{C}-\mathrm{H}_{2} \mathrm{C}-\mathrm{C}=\mathrm{O}, 4 \mathrm{H}, \mathrm{m}\right), 1.54-1.49\left(-\mathrm{CH}_{2}-\mathrm{CH}-\right.$ $\left.\mathrm{CH}_{2}, 4 \mathrm{H}, \mathrm{m}\right), 1.45-1.24\left(-\left(\mathrm{CH}_{2}\right)_{6}-\mathrm{CH}_{2}-\mathrm{CH}-\mathrm{CH}_{2}-\left(\mathrm{CH}_{2}\right)_{5}\right.$ and $\left.\mathrm{S}-\mathrm{CH}_{2}-\left(\mathrm{CH}_{2}\right)_{10}-\mathrm{CH}_{3}, 42 \mathrm{H}, \mathrm{m}\right)$, $0.88\left(-\mathrm{CH}_{2}-\mathrm{CH}_{3}\right.$ and $\left.\mathrm{S}-\mathrm{CH}_{2}-\left(\mathrm{CH}_{2}\right)_{11}-\mathrm{CH}_{3}, 6 \mathrm{H}, \mathrm{t}, \mathrm{J}=6.4 \mathrm{~Hz}\right)$.

\section{Synthesis of alkyl sulfur-functionalized oleic acid-based polymethacrylates}

\section{Synthesis of poly(2-(methacryloyloxy)ethyl 9-(octadecylthio)oleate) (PMAEO $_{\text {SC18 }}$ )}

MAEO $_{\mathrm{SC} 18}(7 \mathrm{mmol}, 3 \mathrm{~g})$ and AIBN $(0.08 \mathrm{mmol}, 12 \mathrm{mg})$ were dissolved in $10 \mathrm{~mL}$ of THF at $60{ }^{\circ} \mathrm{C}$. The reaction mixture was then added into a two necked flask equipped with a magnetic bar and purged with $\mathrm{N}_{2}$ gas for 20 min. After reaching a maximum of monomer conversion, the reaction mixture was quenched by cooling in liquid nitrogen and purified by precipitation in $\mathrm{MeOH}$ at least two times to yield a viscous liquid. The resulting polymer 
$\mathrm{PMAEO}_{\mathrm{SC} 12}$ was dried under vacuum for $5 \mathrm{~h}$ at $80{ }^{\circ} \mathrm{C}$ (yield $=79 \%$ ). Its chemical structure was confirmed by ${ }^{1} \mathrm{H}$ NMR spectroscopy (Fig. 2, (C)).

PMAEO SC18: $\delta$ (ppm, $\left.400 \mathrm{MHz}, \mathrm{CDCl}_{3}\right)$ : 4.24-4.12 ( $\left.\mathrm{OCH}_{2}-\mathrm{CH}_{2} \mathrm{O}, 4 \mathrm{H}, \mathrm{m}\right), 2.54-2.52$ (-S$\mathrm{CH}-, 1 \mathrm{H}, \mathrm{m}), 2.47-2.43$ (-CH $\left.\mathbf{C}_{2}-\mathrm{S}-, 2 \mathrm{H}, \mathrm{m}\right), 2.33-2.30\left(\mathrm{O}=\mathrm{C}-\mathrm{CH}_{2}, 2 \mathrm{H}, \mathrm{m}\right), 1.94-1.92\left(\mathrm{CH}_{3}-\mathrm{C}\right.$, m), 1.63-1.59 (-CH $\mathbf{C H}_{2}-\mathrm{C}$ and $\left.\mathbf{H}_{2} \mathrm{C}-\mathrm{H}_{2} \mathrm{C}-\mathrm{C}=\mathrm{O}, 4 \mathrm{H}, \mathrm{m}\right), 1.56-1.54\left(-\mathrm{CH}_{2}-\mathrm{CH}-\mathrm{CH}_{2}, 4 \mathrm{H}, \mathrm{m}\right), 1.30-$ $1.26\left(-\left(\mathrm{CH}_{2}\right)_{6}-\mathrm{CH}_{2}-\mathrm{CH}-\mathrm{CH}_{2}-\left(\mathrm{CH}_{2}\right)_{5}\right.$ and $\left.\mathrm{S}_{-}-\mathrm{CH}_{2}-\left(\mathrm{CH}_{2}\right)_{16}-\mathrm{CH}_{3}, 54 \mathrm{H}, \mathrm{m}\right), 1.02$ and $0.88\left(\mathrm{CH}_{3^{-}}\right.$ $\mathrm{C}, 3 \mathrm{H}, \mathrm{m}), 0.88\left(-\mathrm{CH}_{2}-\mathrm{CH}_{3}\right.$ and $\left.\mathrm{S}-\mathrm{CH}_{2}-\left(\mathrm{CH}_{2}\right)_{16}-\mathrm{CH}_{3}, 6 \mathrm{H}, \mathrm{t}\right)$.

\section{Synthesis of poly(2-(methacryloyloxy)ethyl 4-( dodecylthio)oleate) (PMAEO $_{\text {SC12 }}$ )}

The polymer was obtained by following the same procedure than the homopolymerization of $\mathrm{MAEO}_{\mathrm{SC} 18}\left(\right.$ yield= $76 \%$ ). Its chemical structure was confirmed by ${ }^{1} \mathrm{H}$ NMR (Fig. SI-2, (B)).

PMAEO $_{\mathrm{SC12}}: \delta$ (ppm, $\left.400 \mathrm{MHz}, \mathrm{CDCl}_{3}\right): 4.24$ and $4.14\left(\mathrm{OCH}_{2}-\mathrm{CH}_{2} \mathrm{O}, 4 \mathrm{H}, \mathrm{m}\right), 2.54-2.51$ (-

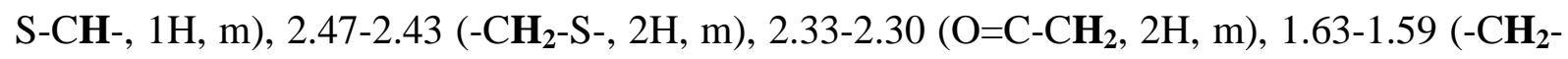
$\mathrm{C}$ and $\left.\mathbf{H}_{2} \mathrm{C}-\mathrm{H}_{2} \mathrm{C}-\mathrm{C}=\mathrm{O}, 4 \mathrm{H}, \mathrm{m}\right), 1.56-1.52\left(-\mathrm{CH}_{2}-\mathrm{CH}-\mathrm{CH}_{2}, 4 \mathrm{H}, \mathrm{m}\right), 1.40-1.26\left(-\left(\mathrm{CH}_{2}\right)_{6}-\mathrm{CH}_{2}-\right.$ $\mathrm{CH}-\mathrm{CH}_{2}-\left(\mathrm{CH}_{2}\right)_{5}$ and $\left.\mathrm{S}-\mathrm{CH}_{2}\left(\mathrm{CH}_{2}\right)_{10}-\mathrm{CH}_{3}, 42 \mathrm{H}, \mathrm{m}\right), 1.02$ and $0.88\left(\mathrm{CH}_{3}-\mathrm{C}, 3 \mathrm{H}, \mathrm{m}\right), 0.88$ ($\mathrm{CH}_{2}-\mathrm{CH}_{3}$ and $\left.\mathrm{S}-\mathrm{CH}_{2}-\left(\mathrm{CH}_{2}\right)_{10}-\mathrm{CH}_{3}, 6 \mathrm{H}, \mathrm{t}\right)$.

\section{Results and discussions}

\section{Synthesis of sulfur-functionalized methacrylate monomers}

\section{Alkyl sulfur-functionalized oleic acid derivatives}

Thiol-ene coupling of oleic acid (OA) was carried out in THF at $70{ }^{\circ} \mathrm{C}$ by using an excess of 1-dodecanethiol (3 eq) and $\operatorname{AIBN}(0.1 \mathrm{eq})$ as thermal initiator (Scheme 1(A)). After $24 \mathrm{~h}$, $70 \%$ of internal double bond were converted and therefore a second AIBN addition ( $0.1 \mathrm{eq})$ was conducted to reach a quantitative conversion after $24 \mathrm{~h}$ more of reaction (Fig. SI-3). 
(A)

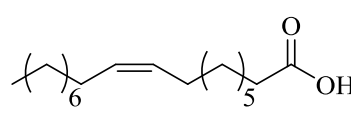<smiles>CC#N</smiles>

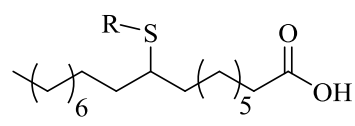

$\mathrm{AO}_{\mathrm{SC} 12}\left(\mathrm{R}=\mathrm{C}_{12} \mathrm{H}_{25}\right)$

$\mathrm{AO}_{\mathrm{SC} 18}\left(\mathrm{R}=\mathrm{C}_{18} \mathrm{H}_{37}\right)$

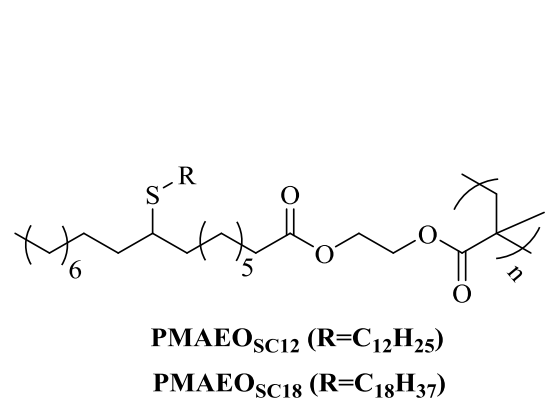

(B)
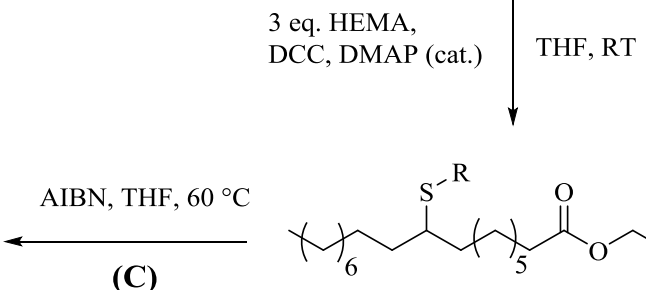

(C)

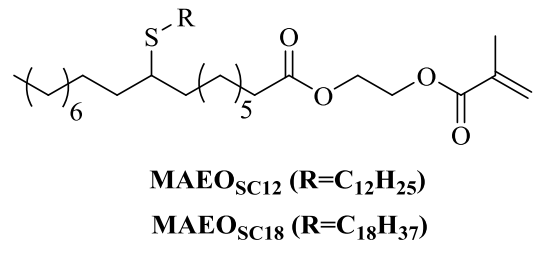

Scheme 1: Thiol-ene coupling on oleic acid internal unsaturations with alkyl thiol SHR $\left(\mathrm{R}=\mathrm{C}_{12} \mathrm{H}_{25}\right.$ or $\mathrm{C}_{18} \mathrm{H}_{37}$ ), (A) Steglich esterification of the resulting derivatives (B), Free radical homopolymerization of alkyl sulfur-functionalized methacrylate monomers (C)

Fig. 2 (B) exhibits the ${ }^{1} \mathrm{H}$ NMR spectra of the $\mathrm{AO}_{\mathrm{SC} 18}$. All peaks have been assigned and confirmed the complete disappearance of both signals $(\mathrm{CH}=\mathrm{CH})$ at $5.34 \mathrm{ppm}$ and $\left(\mathrm{CH}_{2}-\mathrm{CH}=\right)$ at $2.01 \mathrm{ppm}$ proved a quantitative conversion of the double bond. Then, the occurrence of the characteristic signals corresponding to the $\mathrm{CH}_{2}-\mathrm{S}$ and the S-CH protons at 2.46 and $2.54 \mathrm{ppm}$ respectively confirmed the alkyl thiol addition onto the oleic acid internal unsaturations. The side-reaction leading to formation of disulfide was not observed. The thiol-ene coupling was also successfully performed with 1-octadecanethiol by following the same procedure. The resulting structure of the final product, $\mathrm{AO}_{\mathrm{SC} 12}$, is shown in Fig. SI-1, (B).

\section{Alkyl sulfur-functionalized methacrylate oleic acid-based monomers}

Both alkyl sulfur-functionalized oleic acid-based derivatives were converted into suitable and novel radically polymerizable monomers by grafting HEMA through Steglich esterification onto their backbones. The reaction was conducted in THF at room temperature and catalyzed via DMAP in the presence of DCC as coupling agent (Scheme 1, (B)). After 24 $\mathrm{h}$, the reaction was completed and the oleic acid derivatives were both quantitatively converted into monomers and purified through liquid-liquid extraction. Fig. 2, (B) shows the ${ }^{1} \mathrm{H}$ NMR spectrum of $\mathrm{MAEO}_{\mathrm{SC} 18}$ monomer where all peaks have been assigned. The 
appearance of the vinyl protons belonging to the methacrylate function at 6.13 and $5.59 \mathrm{ppm}$ as well as the methyl protons of the methacrylate function at $1.95 \mathrm{ppm}$ confirmed the effectiveness of the functionalization. The spectrum of monomer $\mathrm{MAEO}_{\mathrm{SC} 12}$ is shown in Fig. SI-2, (A).

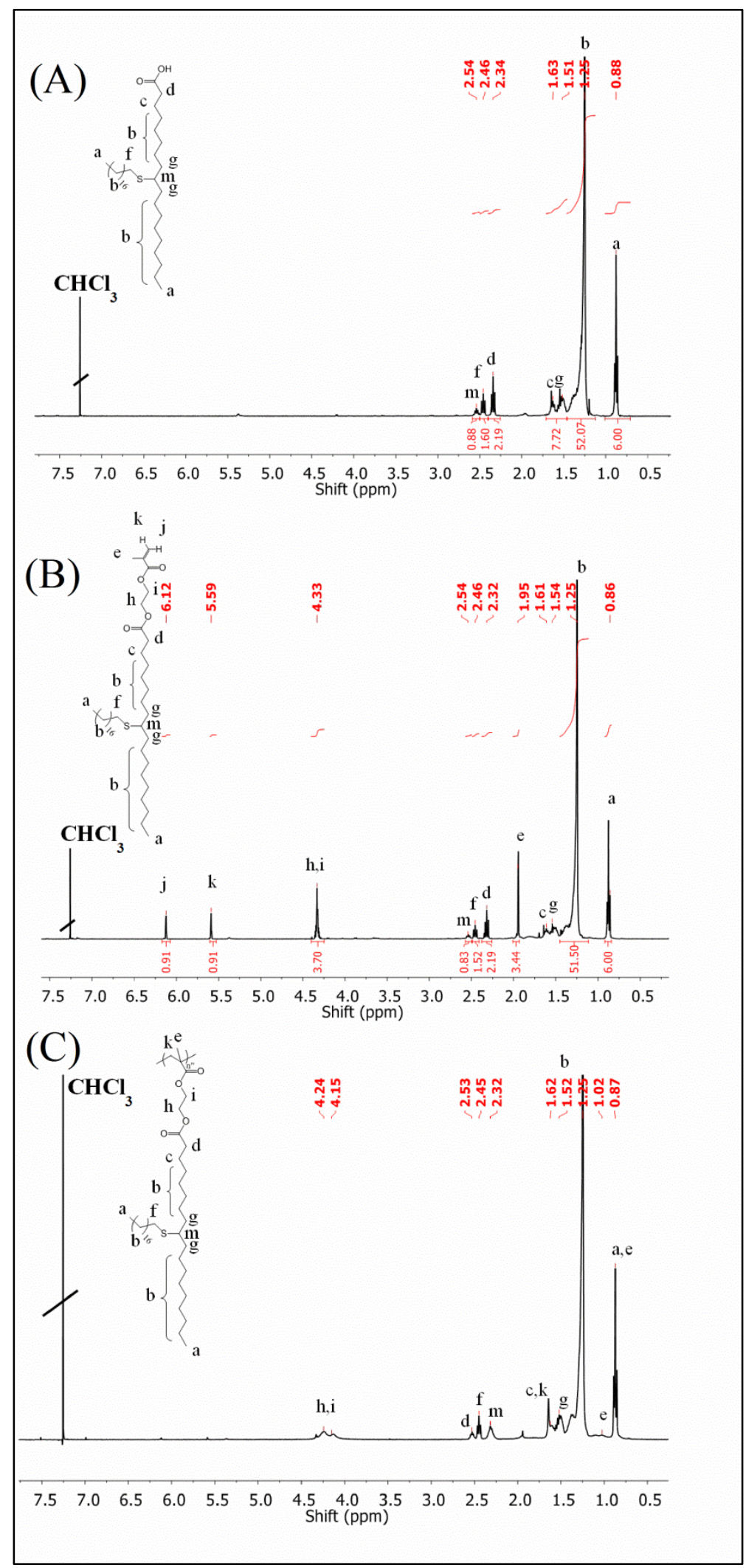


Fig. 2: ${ }^{1} \mathrm{H}$ NMR spectra of $\mathrm{AO}_{\mathrm{SC} 18}(\mathrm{~A}) \mathrm{MAEO}_{\mathrm{SC} 18}(\mathrm{~B}), \mathrm{PMAEO}_{\mathrm{SC} 18}(\mathrm{C}) \mathrm{CDCl}_{3}$

\section{Alkyl sulfur-functionalized oleic acid-based polymethacrylates}

The alkyl sulfur-functionalized methacrylate monomers, $\mathrm{MAEO}_{\mathrm{SC} 12}$ and $\mathrm{MAEO}_{\mathrm{SC} 18}$, were homopolymerized through radical polymerization in THF at $60{ }^{\circ} \mathrm{C}$ by using $\mathrm{AIBN}$ as radical source (Scheme 1, (C)). The rate of polymerization was monitored by ${ }^{1} \mathrm{H}$ NMR spectroscopy by following the decrease in intensity of the methacrylate proton signals. Despite the difference of chain length in their structures, both monomers exhibited similar reactivity and conversion (around $90 \%$ ) into polymers after $24 \mathrm{~h}$ of reaction as shown in Fig. 3. Fig. 2, (C) shows the ${ }^{1} \mathrm{H}$ NMR spectrum of $\mathrm{PMAEO}_{\mathrm{SC} 18}$ while that of $\mathrm{PMAEO}_{\mathrm{SC} 12}$ is shown in Fig. SI-2, (B). The complete disappearance of peaks assigned to the vinyl protons of the methacrylate group indicated the efficient removal of unreacted monomer after precipitation in cold methanol. The $\mathrm{O}-\mathrm{CH}_{2}$ protons of side chain appeared at 4.24 and $4.14 \mathrm{ppm}$ while methyl protons of the polymer backbone are assigned to the peak between 1.02 and $0.88 \mathrm{ppm}$. The resulting alkyl sulfur-functionalized poymers were obtained with a weight average molecular weight $\left(\overline{M_{w}}\right)$ of 146 and $155 \mathrm{~kg} \cdot \mathrm{mol}^{-1}$ and a broad dispersities (Đ) of 3.2 and 3.5 for respectively $\mathrm{PMAEO}_{\mathrm{SC} 12}$ and $\mathrm{PMAEO}_{\mathrm{SC} 18}$ (determined through $\mathrm{SEC}$ measurements). They both displayed suitable high molar masses for VII application as demonstrated in previous studies (Lomège et al., 2018; Lomège et al., 2019).

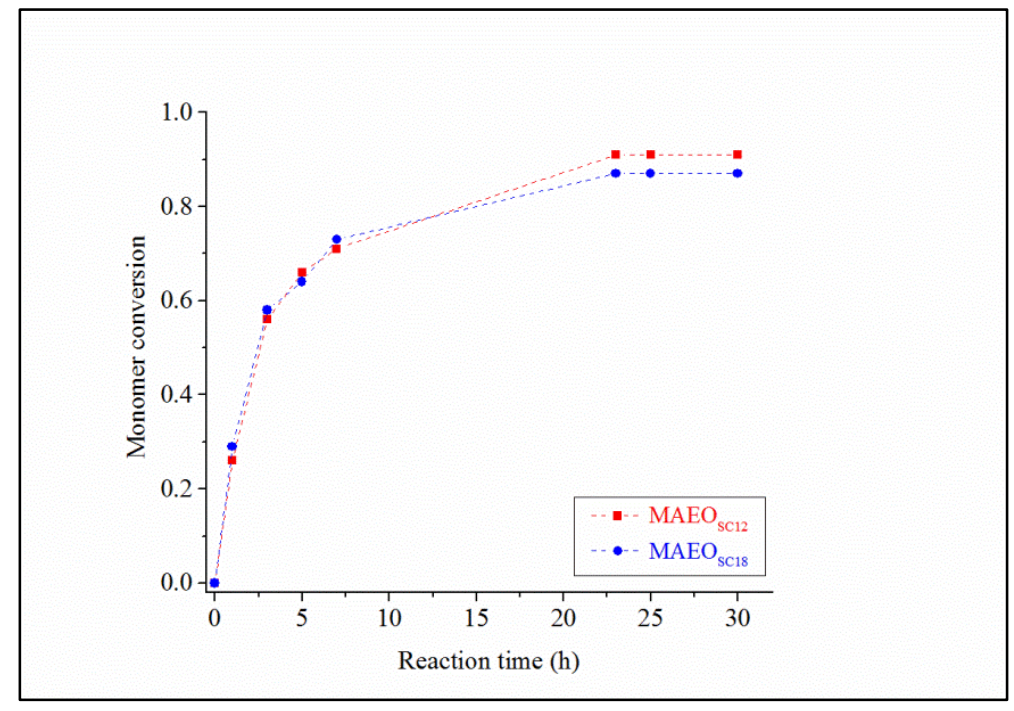

Fig. 3: $\mathrm{MAEO}_{\mathrm{SC} 12}$ and $\mathrm{MAEO}_{\mathrm{SC} 18}$ conversions versus time during the radical polymerization 


\section{Thermal properties of the alkyl sulfur-functionalized oleic acid- based polymethacylates}

In order to confirm that the synthesized polymers have enough thermal stability to be used as additives in the selected lubricating oil for the study, thermogravimetric analysis (TGA) was performed (Fig. 4). The results indicated that the temperature at $5 \%$ weight loss $\left(\mathrm{T}_{\mathrm{d} 5 \%}\right)$ was around $280{ }^{\circ} \mathrm{C}$ for both alkyl sulfur-functionalized polymethacrylates while the temperature at $5 \%$ weight loss was $200{ }^{\circ} \mathrm{C}$ for the mineral paraffinic oil (MPO). Therefore, as polymers have a higher thermal stability than the lube oil, they can be suitably used as additives in this oil. Moreover, the alkyl sulfur-functionalized polymers have a higher thermal stability than PMAEO described in our previous study (Lomège et al., 2018).

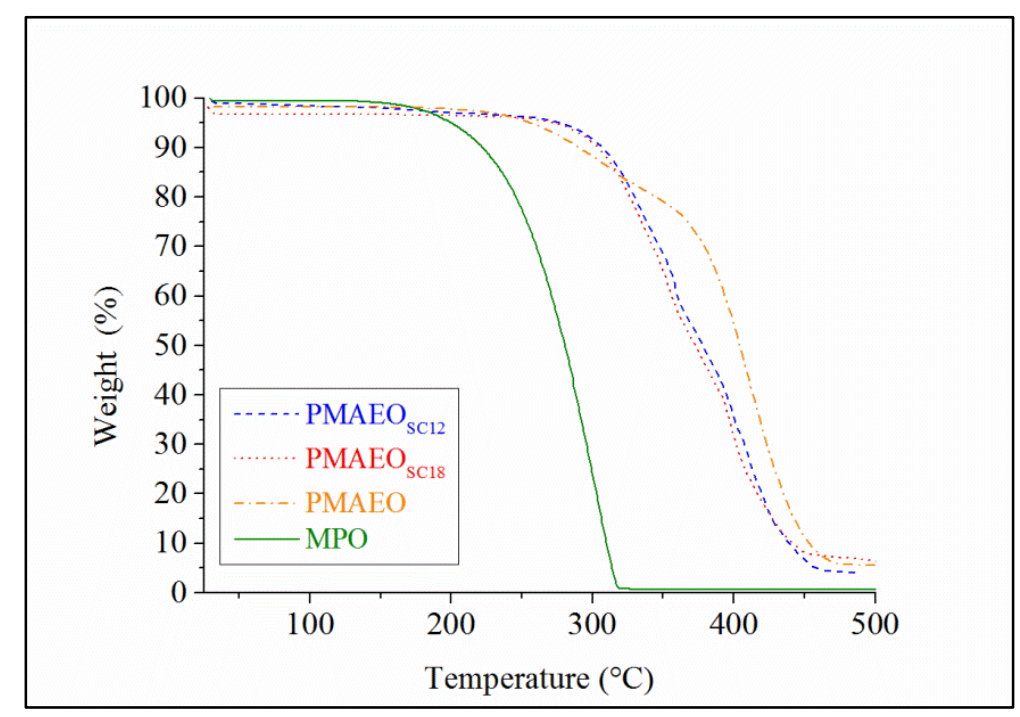

Fig. 4: TGA analysis of the alkyl sulfur-functionalized polymethacrylates and the lube oil

The thermal behavior of the alkyl sulfur-functionalized polymers has been also characterized by DSC analyses. Both homopolymers demonstrated crystalline behaviors at $50{ }^{\circ} \mathrm{C}$ and $-20{ }^{\circ} \mathrm{C}$ for respectively $\mathrm{PMAEO}_{\mathrm{SC} 12}$ and $\mathrm{PMAEO}_{\mathrm{SC} 18}$ (Fig. 5) while PMAEO did not. According to the results, the longer the alkyl chain, the higher the crystallization temperature $\left(T_{c}\right)$ of the polymers, in accordance with the literature (Çayli et al., 2008). The $T_{c}$ values of both polymers are lower than the pour point of the lube oil which is around $-15^{\circ} \mathrm{C}$. Therefore, they should not negatively affect the rheological flow behavior of oil at temperatures above the oil pour point. In summary, the alkyl sulfur-functionalized polymers demonstrated suitable thermal properties to be used in MPO over a wide range of operating temperatures. 


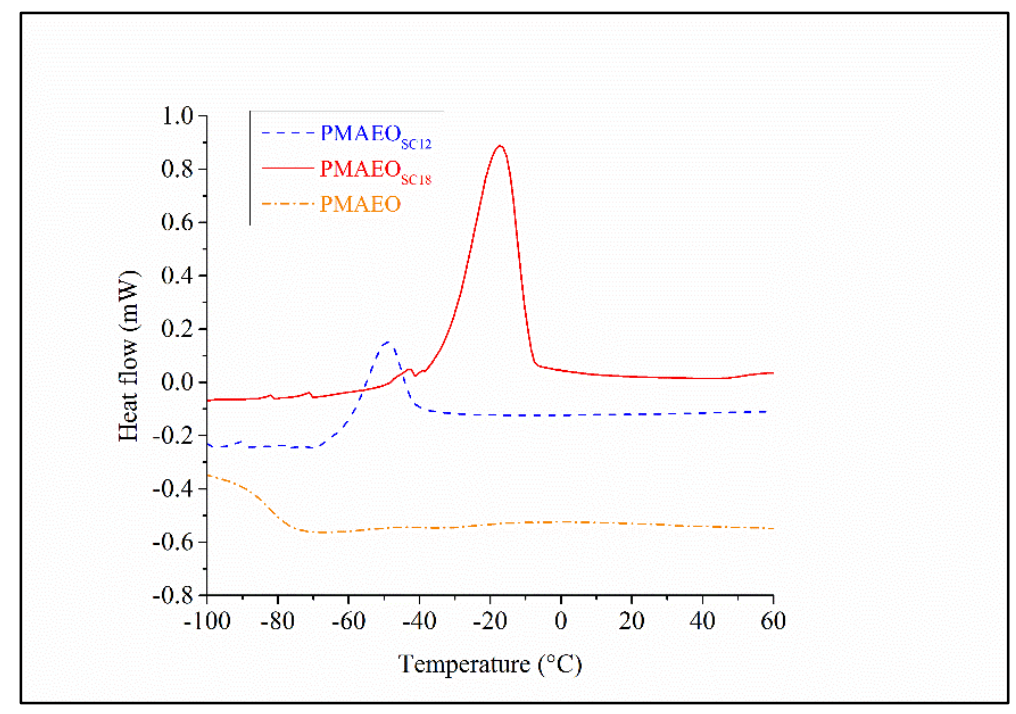

Fig. 5: DSC analyses of the alkyl sulfur-functionalized polymers

\section{Evaluation of the alkyl sulfur-functionalized polymethacrylates as VII}

\section{Rheological viscosity dynamic measurements}

The rheological behavior of oil-polymer blends ( 5 wt. \%) was studied between 0 and 100 ${ }^{\circ} \mathrm{C}$ in order to evaluate the tendency of polymer thickening power with temperature and therefore determine if they have similar properties than common PMAs. For this purpose, dynamic viscosity measurements of oil-polymer blends with temperature were firstly performed and then the relative viscosity (RV) between MPO and MPO-polymer blends was calculated and plotted versus temperature. The calculated RV represents the polymer contribution on oil viscosity. Therefore, the RV should increase with the temperature if the incorporated polymer in oil behaves as en efficient VII (Covitch et al., 2015).

According to the rheological measurements shown in Fig. 6, similar behavior in temperature was observed for both alkyl sulfur-functionalized polymers. Indeed, the influence of these polymers on the viscosity of MPO was more important at high temperature than at low temperature, which is characteristic of common polymer VII additives. For instance, the $\mathrm{RV}$ of MPO-PMAEO $\mathrm{SC} 18_{8}$ blend was improved from 1.54 at $20{ }^{\circ} \mathrm{C}$ to 1.90 at $100{ }^{\circ} \mathrm{C}$. These results can be assigned to a coil polymer expansion with temperature due to the gradual increase of polymer solubility in MPO. Moreover, the data indicated that the longer the alkyl chain of the grafted alkyl thiol on the polymer backbone, the higher the improvement of the 
polymer thickening power with temperature. Indeed, while the RV improvement between 0 and $100{ }^{\circ} \mathrm{C}$ was 0.26 for $\mathrm{PMAEO}_{\mathrm{SC} 12}$, it was 0.36 for $\mathrm{PMAEO}_{\mathrm{SC} 18}$. This result may be also explained by the slightly lower molar mass of $\mathrm{PMAEO}_{\mathrm{SC} 12}\left(\overline{M_{w}}=146 \mathrm{~kg} \cdot \mathrm{mol}^{-1}, \mathrm{Ð}=3.2\right)$ compared to $\mathrm{PMAEO}_{\mathrm{SC} 18}\left(\overline{M_{w}}=155 \mathrm{~kg} \cdot \mathrm{mol}^{-1}, \mathrm{Ð}=3.5\right)$ which may induce a lower coil size dimension and therefore a lower contribution on oil viscosity as previously reported (Lomège et al., 2018).

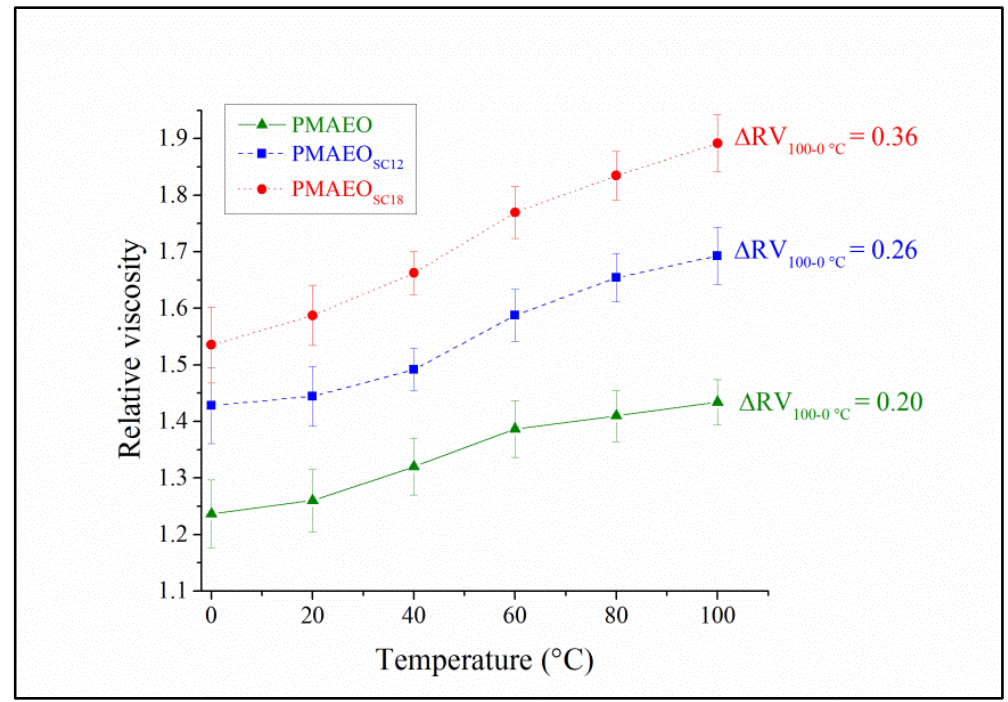

Fig. 6: RV of oil/alkyl sulfur-functionalized polymer blends vs temperature in MPO

Finally, the behavior of these polymers with temperature was also compared to the previously reported poly(2-(methacryloyloxy)ethyl oleate) (PMAEO, $\overline{M_{w}}=160 \mathrm{~kg} \cdot \mathrm{mol}^{-1}, \mathrm{Ð}=$ 3.6) in order to demonstrate the importance of the additional grafted alkyl chain (Lomège et al., 2018). According to the Fig. 6, the alkyl sulfur-functionalized polymers have shown a better thickening power improvement with temperature compared to PMAEO $\left(\mathrm{RV}_{100-0}{ }^{\circ} \mathrm{C}=\right.$ 0.20) despite their slightly lower molar masses. In fact, the additional aliphatic chains on their backbone have promoted the interactions with the aliphatic chains of MPO, inducing a higher contribution on oil viscosity, especially at high temperature where the solubility of polymer is enhanced. In the meantime, despite their higher RV improvement with temperature, the thickening power of alkyl sulfur-functionalized polymers is also higher at low temperature compared to PMAEO and may induce more energy to put the oil in motion at those low operating temperatures. However, in case high viscosity might be problematic at low temperature for some lubricant applications (such as engine oils), the thickening power of the synthesized polymers can be easily modulated by varying the polymer concentration in oil 
allowing to select the proper viscosity according to the desired application as previously reported (Lomège et al., 2018).

\section{Viscosity Index (VI) calculations}

The alkyl sulfur-functionalized homopolymers were tested for their effectiveness as VII by calculating the VI of the pure oil and those of oil-polymer blends owing to the ASTM D227010 method. This method includes the determination of the kinematic viscosities of the different lubricant formulations at 40 and $100{ }^{\circ} \mathrm{C}$. The resulting data are shown in Table 2 and indicated the effectiveness of adding alkyl sulfur-functionalized polymers for improving the MPO VI. Indeed, while the MPO has an initial VI of 102, it was only increased to 154 by adding PMAEO in the lube oil compared to 186 and 195 by adding alkyl sulfur-functionalized homopolymers respectively $\mathrm{PMAEO}_{\mathrm{SC} 12}$ and $\mathrm{PMAEO}_{\mathrm{SC} 18}$ in the lube oil. The improvement of VI was more pronounced in the case of the homopolymer containing the longer alkyl sulfur as it induced more interactions with the paraffin content of the MPO and therefore a higher thickening power improvement with temperature. These results showed that the polymer confers a higher viscosity to oil and that this contribution is higher at high temperature, which is the demonstration of a VII. Hence, as the addition of $\mathrm{PMAEO}_{\mathrm{SC} 18}$ in MPO induced the highest increase of relative viscosity with the temperature $\left(\Delta R V_{100-0}{ }^{\circ} \mathrm{C}=0.36\right)$, it demonstrated the best VII efficiency

Table 2: Kinematic viscosities and viscosity index measurements of pure MPO and oil-polymer blends

\begin{tabular}{|c|c|c|c|c|}
\hline Oil-polymer blends & $\begin{array}{c}\mathbf{K V ~ 4 0}{ }^{\circ} \mathbf{C} \\
\left(\mathbf{m m}^{\mathbf{2}} \cdot \mathbf{s}^{-\mathbf{1}}\right)\end{array}$ & $\begin{array}{c}\mathbf{K V ~ 1 0 0}{ }^{\circ} \mathbf{C} \\
\left(\mathbf{m m}^{\mathbf{2}} \cdot \mathbf{s}^{-\mathbf{1}}\right)\end{array}$ & Viscosity Index & $\Delta \mathbf{R V}_{\mathbf{1 0 0 - 0}}{ }^{\circ} \mathbf{C}$ \\
\hline Pure MPO & 26.92 & 4.87 & 102 & - \\
\hline MPO + PMAEO & 35.80 & 6.91 & 154 & 0.20 \\
\hline MPO + PMAEO & 40.11 & 8.23 & 186 & 0.26 \\
\hline MPO + PMAEO & 44.69 & 9.25 & 195 & 0.36 \\
\hline
\end{tabular}




\section{Conclusion}

Viscosity Index Improvers (VIIs) from oleic acid for mineral paraffinic lube oils have been reported in this work. The synthesizing process began by the successful thiol-ene coupling of oleic acid with either 1-dodecanethiol or 1-octadecanethiol followed by the quantitative methacrylation of the resulting derivatives through Steglich esterification. The alkyl sulfurfunctionalized oleic acid-based methacrylate monomers have shown a good reactivity through radical polymerization leading to high molecular weight polymers which is desirable for the targeted application. The good thermal stability of these homopolymers coupled with their similar "comb-like" structures than current PMAs as well as their high hydrophobicity made them suitable candidates for being evaluated as VII in MPO. Therefore, the behavior the resulting polymers in MPO as a function of temperature was characterized by rheological measurements and demonstrated that their thickening power in the lube oil was significantly improved as the temperature rises. According to the results, the longer the aliphatic chains contained in the polymer additive backbone, the greater the relative viscosity improvement in temperature. Moreover, viscosity index measurements have confirmed the ability of the alkyl sulfur-functionalized polymers to considerably improve the initial lube oil's VI. Consequently, from the above discussion, it is clear that both alkyl sulfur-functionalized oleic acid-based polymethacrylates have performed as excellent VII with high thickening power in a mineral paraffinic oil (MPO) and may be considered as promising alternative to current PMAs.

\section{Acknowledgment}

This work was performed, in partnership with the SAS PIVERT, within the frame of the French Institute for the Energy Transition (Institut pour la Transition Energétique (ITE) P.I.V.E.R.T. (www.institut-pivert.com) selected as an Investment for the Future ("Investissements d'Avenir"). This work was supported, as part of the Investments for the Future, by the French Government under the reference ANR-001-01. The authors have declared no conflict of interest.

\section{Conflict of Interest}

The authors declare that they have no conflict of interest. 


\section{References}

Ahmed, M. R.; Mohammed, A. H. A.-K.; A.hamad (2017) M. Synthesis, Characterization and Performance Evaluation of Poly Octadecyl Methacrylate and Poly Octadecyl Methacrylate-CoMethylmethacrylate as an Additive for Lubricating Oil. IOSR Journal of Applied Chemistry, 10:50-58.

Akhmedov, A. I.; Buniyat-Zade, I. A. (1993) Principles of Synthesis of Viscosity Index Improvers of the Poly(Alkyl Methacrylate) Type. Chem Technol Fuels Oils, 29:207212.

Almeida, A. P. P.; Oliveira, A. P. L. R. de; Erbetta, C. D. C.; Sousa, R. G. de; Freitas, R. F. de S.; Silva, M. E. S. R. (2014) Rheological Study of Polymers Used as Viscosity Index Improvers for Automotive Lubricant Oils. Journal of Modern Physics, 05:1085-1093

Bantchev, G. B.; Kenar, J. A.; Biresaw, G.; Han, M. G. (2009) Free Radical Addition of Butanethiol to Vegetable Oil Double Bonds. J. Agric. Food Chem., 57:1282-1290.

Bartz, W. J. Tribology, Lubricants and Lubrication Engineering — a Review (1978) Wear, 49:1-18.

Biresaw, G.; Bantchev, G. B.; Cermak, S. C. (2011) Tribological Properties of Vegetable Oils Modified by Reaction with Butanethiol. Tribology Letters, 43:17-32.

Cai, G.; Zhang, L.; Ma, L.; Eli, W. (2015) Synthesis and Characterization of Polybutylacrylate Viscosity Index Improver with Anti-Wear Function. Lubrication Science, 27:209-216

Caillol, S.; Desroches, M.; Boutevin, G.; Loubat, C.; Auvergne, R.; Boutevin (2012) B. Synthesis of New Polyester Polyols from Epoxidized Vegetable Oils and Biobased Acids. European Journal of Lipid Science and Technology, 114:1447-1459

Çayli, G.; Meier, M. A. R. (2008) Polymers from Renewable Resources: Bulk ATRP of Fatty Alcohol-Derived Methacrylates. European Journal of Lipid Science and Technology, 110:853-859

Covitch, M. J.; Trickett, K. J. (2015) How Polymers Behave as Viscosity Index Improvers in Lubricating Oils. Advances in Chemical Engineering and Science, 05:134-151.

Desroches, M.; Caillol, S.; Lapinte, V.; Auvergne, R.; Boutevin, B. (2011) Synthesis of Biobased Polyols by Thiol-Ene Coupling from Vegetable Oils. Macromolecules, 44:2489-2500

Eskici, M.; Sabih Özer, M.; Atik, E.; Beşergil, B. (2008) Study on Lubricant Quality and Its Effect on Engine Component Performance. Ind Lubrication and Tribology, 60:172177.

Ghosh, P.; Karmakar, G. (2014) Evaluation of Sunflower Oil as a Multifunctional Lubricating Oil Additive. International Journal of Industrial Chemistry, 5:7-17.

Ghosh, P. (2014) Soybean Oil as a Biocompatible Multifunctional Additive for Lubricating Oil. American Chemical Society, 19-25.

Ghosh, P.; Hoque, M.; Karmakar, G.; Yeasmin, S. (2017) Castor Oil Based Multifunctional Greener Additives for Lubricating Oil. Current Environmental Engineering, 4:197-206.

Ghosh, P.; Dey, K.; Upadhyay, M.; Das, T. (2017) Multifunctional Biodegradable Lube Oil Additives: Synthesis, Characterization, and Performance Evaluation. Petroleum Science and Technology, 35:66-71.

Horne, W. L. V. (1949) Polymethacrylates as Viscosity Index Improvers and Pour Point Depressants. Ind. Eng. Chem., 41:952-959 
Hoyle CE., Bowman CN. (2010) Angewandte Chemie, 49:1540-1573

Ionescu, M.; Radojčić, D.; Wan, X.; Petrović, Z. S.; Upshaw, T. A. (2015) Functionalized Vegetable Oils as Precursors for Polymers by Thiol-Ene Reaction. European Polymer Journal, 67:439-448

Lligadas, G.; Ronda, J. C.; Galià, M.; Cádiz, V. (2013) Renewable Polymeric Materials from Vegetable Oils: A Perspective. Materials Today, 16:337-343.

Lomège, J.; Negrell, C.; Robin, J.-J.; Lapinte, V.; Caillol, S. (2018) Fatty Acid-Based Methacrylate Polymers as Viscosity Modifiers for Mineral Oils. Green Materials, 6: 97-107.

Lomège, J.; Negrell, C.; Robin, J.-J.; Lapinte, V.; Caillol, S. (2019) Oleic Acid-Based Poly(Alkyl Methacrylate) as Bio-Based Viscosity Control Additive for Mineral and Vegetable Oils. Polymer Engineering \& Science, 59:E164-E170

Martini, A.; Ramasamy, U. S.; Len, M. (2018) Review of Viscosity Modifier Lubricant Additives. Tribol Lett, 66:58-72.

Mohamad, S. A.; Ahmed, N. S.; Hassanein, S. M.; Rashad, A. M. (2012) Investigation of Polyacrylates Copolymers as Lube Oil Viscosity Index Improvers. Journal of Petroleum Science and Engineering, 100:173-177.

Montero de Espinosa, L.; Meier, M. A. R. (2011) Plant Oils: The Perfect Renewable Resource for Polymer Science?! European Polymer Journal, 47:837-852.

Müller, H. G. (1978) Mechanism of Action of Viscosity Index Improvers. Tribology International, 11:189-192.

Neveu, C. D.; Sondjaja, R.; Stöhr, T.; Iroff, N. J. (2012) Lubricant and Fuel Additives Based on Polyalkylmethacrylates. In Polymer Science: A Comprehensive Reference; Elsevier,; pp 453-478.

Pelletier, H.; Belgacem, N.; Gandini, A. (2006) Acrylated Vegetable Oils as Photocrosslinkable Materials. Journal of Applied Polymer Science, 99:3218-3221

Ramasamy, U. S.; Lichter, S.; Martini, A. (2016) Effect of Molecular-Scale Features on the Polymer Coil Size of Model Viscosity Index Improvers. Tribology Letters, 62:1-7.

Rattan, G.; Parihar, N. S. (2017) Viscosity Index Improver for Engine Oils: An Experimental Study. Journal of Chemical and Petroleum Engineering, 51:39-45.

Selby, T. W. (1958) The Non-Newtonian Characteristics of Lubricating Oils. A S L E Transactions, 1:68-81.

Stanciu, I. (2012) Methods for Calculating Viscosity Index Hydraulic Oil. Journal of Science and Arts, 2:177-180.

Stemmelen, M.; Pessel, F.; Lapinte, V.; Caillol, S.; Habas, J.-P.; Robin, J.-J. (2011) A Fully Biobased Epoxy Resin from Vegetable Oils: From the Synthesis of the Precursors by Thiol-Ene Reaction to the Study of the Final Material. Journal of Polymer Science Part A: Polymer Chemistry, 49:2434-2444.

Vidal F., Gowda RR., Chen EYX (2015) Journal of the American Chemical Society, 137:9469-9480

Vidal F., Falivene L., Caporaso L., Luigi Cavallo L., Chen EYX (2016) Journal of the American Chemical Society, 138:9533-9547 